\author{
Available online at JSJ: Jurnal Studi Jurnalistik \\ http://journal.uinjkt.ac.id/index.php/jsj \\ JSJ: Jurnal Studi Jurnalistik, 2 (2), 2020, 146-156
}

\title{
Pengaruh Terpaan Kanal Detikpemilu Detik.Com Terhadap Tingkat Pengetahuan Pemilih Pemula
}

\author{
Fitria Apriliyanti, Uljanatunnisa, Azwar \\ Prodi Ilmu Komunikasi, FISIP, UPN Veteran Jakarta. \\ aprilianyanti_fitria@yahoo.com \\ azwarstmalaka@upnvj.ac.id \\ uljanatunnisa@gmail.com
}

\begin{abstract}
Abstrak
Kemajuan teknologi telah memberikan kemudahan bagi masyarakat untuk memenuhi kebutuhan informasi, tidak terkecuali informasi tentang pemilihan umum atau seputar kampanye dan debat calon presiden dan wakil presiden pada tahun 2019. Melalui Kanal DetikPEMILU, portal berita Detikcom menyediakan kanal khusus tentang informasi pemilu. Penelitian ini bertujuan untuk melihat pengaruh terpaan kanal DetikPemilu Detik.com Periode Februari 2019 terhadap tingkat pengetahuan pemilih pemula. Terpaan media massa dan tingkat pengetahuhan pemilu menjadi konsep yang digunakan dalam penelitan ini, sementara pendekatan kuantitatif eksplanatif merupakan metode yang dipilih untuk melihat ada tidaknya pengaruh terpaan terhadap tingkat pengetahuan pemilih pemula. Sampel pada penelitian ini adalah siswa/i kelas XII SMAN 12 Tangerang Selatan sebanyak 76 responden yang dipilih menggunakan teknik purposive sampling. Hasil uji pengaruh diketahui memiliki pengaruh yang dibuktikan dengan nilai Uji t 7,678 > t tabel 1,666, sehingga dapat disimpulkan Ho ditolak dan Ha diterima, yang berarti terpaan kanal DetikPEMILU periode Februari 2019 pada portal berita Detikcom berpegaruh terhadap tingkat pengetahuan pemilih pemula siswa/i kelas XII SMAN 12 Tangerang Selatan.
\end{abstract}

Kata Kunci : Pemilih Pemula, Rubrik Pemilu, Tingkat Pengetahuan.

Permalink/DOI: http://doi.org/10.15408/jsj.v2i2.17643

\section{Pendahuluan}

Pesta Demokrasi atau Pemilihan Umum sudah di depan mata, acara akbar lima tahun sekali ini menjadi topik hangat yang selalu menjadi perbicangan tidak terkecuali bagi pemilih pemula. Pada Pemilu tahun 2019 masyarakat Indonesia yang genap berusia 17 tahun memang telah diberikan jaminan untuk 
menyalurkan aspirasi mereka, sesuai dengan UU No. 7 Tahun 2017.

Secara kuantitatif jumlah pemilih pemula tahun 2019 ini cukup banyak, seperti dilansir dari Detik.com bahwa per 1 Januari 2018 hingga 17 April 2019 jumlah pemilih pemula sebanyak 5.085.887 Jiwa (Detik.com). data tersebut mengambarkan bahwa suara mereka tentunya berpengaruh signifikan terhadap kemenangan pasangan calon presiden dan wakil.

Tetapi dengan meningkatnya jumlah pemilih pemula, ternyata tidak diimbangi dengan realisasi partisipasi pemilih. Menurut Antar Venus bahwa ketidaktahuan pemilih pemula terhadap partai ataupun calon anggota menyebabkan keengganan mereka untuk berpartisipasi dalam pemilu (liputan6.com/).

Olehnya, untuk mengantisipasi hal tersebut dibutuhkan penyebaran informasi yang merata, bukan hanya melalui media konvensional saja akan tetapi distribusi informasi baiknya juga disebarkan melalui media baru. Karena saat ini medium internet, menjadi salah satu medium yang paling sering digunakan oleh generasi milenial.

Berdasarkan Survei Asosiasi Penyelenggara Jasa Internet Indonesia (APJI) bahwa sekitar 79, 23\% pengguna internet merupakan siswa SMA atau sederajat. Sedangkan hasil survei pengguna berdasarkan usia, kelompok usia dengan penggunaan internet tertinggi adalah kelompok usia 13 - 18 tahun yaitu sebanyak 75,50\%, kemudian di posisi kedua ada pada kelompok usia 19 - 35 tahun sebanyak 74,23 \%, sedangkan pada posisi ketiga dengan kelompok usia 36 - 54 tahun memiliki pengguna sebanyak 44,06\% dan adapun pada kelompok usia diatas 54 tahun memiliki $15,72 \%$ pengguna.

Hasil survei di atas menunjukan dengan tingginya jumlah usia pemilih pemula dalam mengakses internet, merupakan peluang besar pada distribusi informasi khususnya tentang pemilu, terlebih lagi berdasarkan laporan Reuters Institute for Study of Jurnalism dengan tajuk Reuters Institute Digital News Report 2016 juga mengemukakan bahwa konsumen dengan usia muda (18-24 tahun) lebih suka mencari berita melalui media digital, sehingga dapat disimpulkan bahwa digitalisasi pada bidang informasi seharusnya memiliki pengaruh yang besar searah dengan meningkatnya pengunaan internet di kalangan pemilih pemula.

Nielsen Indonesia tahun 2017 juga menyatakan bahwa di Indonesia, pembaca media online lebih banyak dibandingkan dengan media konvensional. Jumlah pembeli koran terus merosot karena masyarakat beranggapan bahwa informasi seharusnya bisa didapat tanpa mengeluarkan biaya di luar pembelian pulsa internet. Saat ini masyarakat lebih memilih membaca koran di kantor, 
sekolah, dan perpustakaan, sehingga tak perlu mengeluarkan biaya lagi. Data tersebut menunjukkan, jumlah pembaca media online jauh lebih banyak dibandingkan pembaca media konvensional sebanyak 4,5 juta orang sedangkan pembaca media online sebanyak 6 juta orang.

Memanfaatkan peluang tersebut, Detik.com berupaya menyediakan kanalkanal berita untuk memudahkan sebuah informasi tentang berbagai hal yang dirangkum dalam satu kesatuan agar mudah dicari dan diakses sesuai dengan temanya. Seperti kanal berita olahraga, hiburan, ekonomi, sosial hingga politik.

Khususnya pada masa kampanye saat ini, situs portal berita Detikcom menjadi satu-satunya portal berita yang menyediakan kanal khusus pemilu yang diberi nama DetikPEMILU. Kanal tersebut berisi semua informasi tentang berbagai macam hal yang berhubungan dengan pemilihan umum, informasi-informasi tentang kedua pasangan calon presiden dan wakil presiden hingga trending topic sesuai dengan isu yang sedang ramai diperbincangan tentang pemilihan umum.

Tujuannya agar para pembaca bisa dengan mudah mencari dan mengakses informasi tentang pemilu secara bebas dan terarah, terutama bagi pelajar yang baru berusia 17 tahun dimana tahun ini merupakan tahun pertama mereka mengikuti pemilihan umum. Adanya Kanal DetikPemilu secara tidak langsung memberikan kemudahan akses dalam mencari informasi dimanapun dan kapanpun sesuai keinginan.

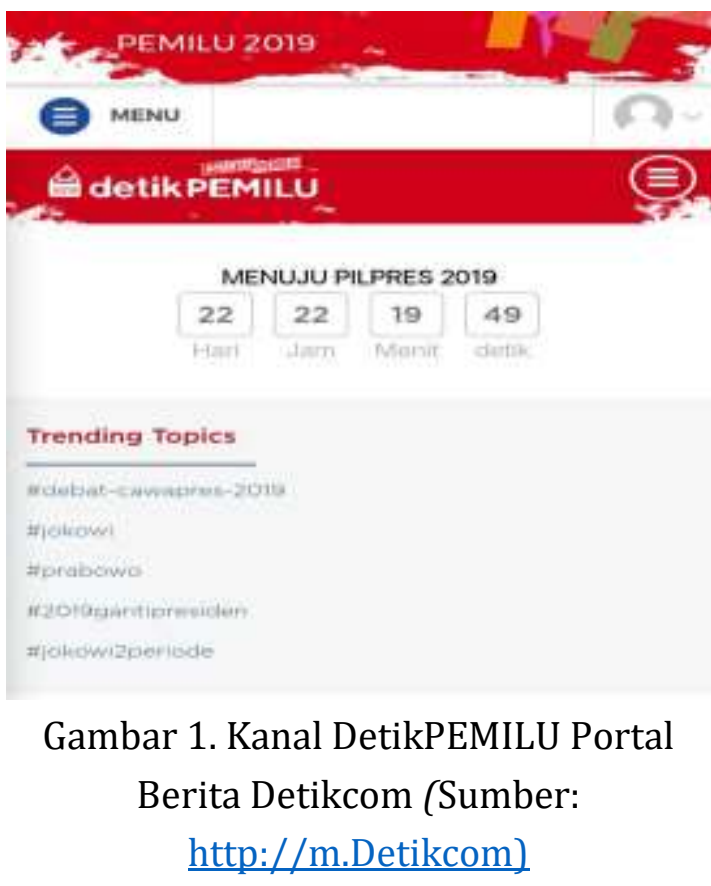

Kanal DetikPEMILU telah hadir sejak Agustus 2018 dengan memuat fiturfitur unik yang bisa membuat pembaca mengenal kedua pasangan calon presiden dan wakil presiden, seperti fitur Profil Calon yang berisi biodata, visi-misi, hingga statistik eletabilitas dari kedua pasangan calon presiden dan wakil presiden. Fitur Hasil Survei yang berisi beberapa lembaga survei yang telah mengukur elektabilitas kedua pasangan calon presiden dan wakil presiden. Kemudian ada fitur Versus yang berisi topik debat antara pendukung, calon legislatif, hingga simpatisan dari kedua calon presiden dan wakil presiden. 
Terakhir, ada fitur Agenda Pemilu yang berisi waktu dan tempat agenda pemilihan umum 2019 dilaksanakan. Tak kalah menarik juga, pada kanal DetikPEMILU terdapat Live Streaming Debat, Quick Count, dan Realcount Pemilu 2019.

Jadi masyarakat bisa dengan mudah menyimak perkembangan Pemilu 2019 secara cepat dan terarah pada satu platform media yang disediakan oleh kanal DetikPEMILU pada portal berita Detikcom

Atas dasar di atas, rumusan masalah dalam penelitian ini adalah apakah kanal DetikPEMILU periode Februari 2019 pada portal berita Detikcom berpengaruh terhadap tingkat pengetahuan pemilih pemula?

\section{Kajian Teoritis}

Jurnalistik

Azwar (2018) menyatakan bahwa secara normatif jurnalistik adalah serangkaian kegiatan untuk mengungkapkan kebenaran, yang dilakukan dengan teknik tertentu. Berdasarkan pemahaman ini, dapat dipahami bahwa jurnalistik merupakan kegiatan menyampaikan berita kepada khalayak, mulai dari kegiatan pencarian data lapangan, mengolahnya menjadi tulisan, sampai menghadirkan kepada khalayak.

Tidak dapat dipungkiri bahwa kegiatan jurnalistik membantu manusia untuk melek akan informasi. Tanpa adanya jurnalistik, manusia tidak akan pernah tau tentang segala informasi yang terjadi di berbagai penjuru dunia, baik kejadian yang belum terjadi, sedang terjadi, maupun yang sudah terjadi.

Media Massa

Berdasarkan pendapat Cangara (2010), media massa adalah sarana untuk menyampaikan pesan yang berhubungan langsung dengan masyarakat luas misalnya radio, televisi, dan surat kabar. Media ialah sarana yang digunakan untuk menyampaikan pesan dari komunikator kepada khalayak, sedangkan pengertian media massa sendiri ialah sarana yang digunakan untuk menyampaikan pesan dari sumber kepada khalayak dengan menggunakan media-media komunikasi seperti surat kabar koran, majalah, radio, televisi, maupun film.

Berita

Ahli-ahli dalam bidang jurnalistik mengatakan bahwa berita adalah apa yang ditulis surat kabar, apa yang disiarkan radio, dan apa yang ditayangkan televisi. Berita menyajikan fakta, tetapi tidak setiap fakta adalah berita. Berita menampilkan fakta, namun tidak semua fakta adalah berita. Berita telah hadir sebagai kebutuhan dasar manusia di seluruh penjuru dunia. Dengan adanya berita, manusia mengetahui segala informasi di berbagai belahan dunia, bahkan dengan mudah karena adanya media massa. Dengan 
adanya berita pula, manusia yang tidak memiliki kedekatan akan informasi yang disampaikan bisa diketahuinya dan dijadikan sebagai acuan dalam bersikap, berperilaku, sampai menentukan sebuah pilihan dalam menunjang kehidupannya.

Terpaan Rubrik/Kanal Media Massa Menurut Ardianto \& Erdinaya (2005), terpaan dapat diartikan sebagai kegiatan mendengar, melihat, dan membaca pesan-pesan yang terdapat di media. Terpaan media berusaha mencari data khalayak tentang penggunaan media, yaitu frekuensi penggunaan media, durasi penggunaan media, maupun macam-macam penggunaan media, seperti koran, majalah, radio, televisi, maupun film dan internet.

Berdasarkan penjelasan diatas, terdapat tiga hal yang terkandung dalam terpaan media, yaitu:

1. Frekuensi Penggunaan Media

Berkaitan dengan data khalayak dalam menonton, membaca, dan mendengar sebuah berita, baik itu berita harian, mingguan, bulanan, maupun tahunan.

2. Durasi Penggunaan Media

Berkaitan dengan jumlah waktu yang digunakan khalayak dalam menggunakan media untuk melihat suatu berita, seperti selama dalam hitungan menit, jam maupun hitungan berapa jam perhari.

3. Atensi Penggunaan Media
Berkaitan dengan perhatian khalayak terhadap berita yang disajikan media, seperti memepetimbangkan isi yang disajikan oleh media.

Mengacu pada penjelasan tentang terpaan rubrik/kanal media massa diatas, dapat diartikan bahwa seberapa jauh khalayak terterpa oleh media yaitu dengan melihat frekuensi, durasi, dan atensi penggunaan media.

Frekuensi dapat dilihat dari berapa kali seseorang membaca kanal DetikPEMILU pada portal berita Detikcom, durasi penggunaan media dapat dilihat dari berapa lama seseorang mengakses kanal DetikPEMILU pada portal berita Detikcom, serta atensi penggunaan media bisa dilihat dari seberapa besar perhatian seseorang terhadap kanal DetikPEMILU pada portal berita Detikcom dengan memberikan penilaian atau sanggahan terhadap berita yang disampaikan.

Pengetahuan

Notoatmojo (2003), mengatakan bahwa pengetahuan ialah hasil dari tahu melalui penginderaan manusia, yaitu indera penglihatan, penciuman, pendengaran, raba, dan rasa. Indera mata dan telinga merupakan indera paling penting yang memberikan sumbangan terbesar dari pengetahuan manusia. Pengetahuan merupakan domain yang sangat penting untuk terbentuknya suatu perilaku dan sikap seseorang. 
Lebih jauh Notoatmojo (2003) menyampaikan bahwa pengetahuan ialah kemampuan seseorang dalam mengingat suatu objek secara langsung dari kesadarannya sendiri. Manusia biasanya akan memerlukan pengetahuan sebelum memilih suatu keputusan untuk mengambil tindakan yang tepat pada situasi yang bermacam-macam karena pengetahuan mendasari manusia untuk megingat dan merepakannya dalam kehidupan sehari-hari, salah satunya dalam menentukan pilihannya untuk presiden dan wakil presiden yang dipilih pada 17 April 2019.

\section{METODE PENELITIAN}

Penelitian ini menggunakan metode penelitian kuantitatif, dengan pendekatan eksplanatif untuk menjelaskan hubungan sebab akibat antara variabel $\mathrm{X}$ dan $\mathrm{Y}$, Penelitian ini akan melihat apakah terdapat pengaruh terpaan kanal DetikPEMILU sebagai variabel X terhadap tingkat pengetahuan pemilih pemula sebagai variabel Y.

Populasi dalam penelitian ini adalah adalah siswa/i kelas XII SMAN 12 Tangerang Selatan yang berjumlah 315 orang, dari populasi tersebut dapat ditarik sampel dengan menggunakan rumus slovin sebanyak 76 responden dengan toleransi kesalahan sebesar $10 \%$. Adapun Penentuan responden menggunakan teknik nonprobability sampling, yaitu purposive sampling.

Hipotesis dalam penelitian ini adalah:

Ha : Terdapat pengaruh terpaan kanal

DetikPEMILU periode Februari 2019 pada portal berita Detikcom terhadap tingkat pengetahuan pemilih pemula.

Ho : Tidak terdapat pengaruh terpaan kanal

DetikPEMILU periode Februari 2019 pada portal berita Detikcom terhadap tingkat pengetahuan pemilih pemula.

Tabel 1. Operasional Variabel X dan Y

\begin{tabular}{|c|c|c|c|}
\hline Variabel & Dimensi & Indikator & Skala \\
\hline $\begin{array}{l}\text { Terpaan Kanal } \\
\text { DetikPEMILU }(X)\end{array}$ & Frekuensi & $\begin{array}{l}\text { Jumlah akses kanal DetikPEMILU } \\
\text { pada portal berita Detikcom }\end{array}$ & \\
\hline $\begin{array}{l}\text { Terpaan dapat } \\
\text { diartikan sebagai } \\
\text { kegiatan mendengar, } \\
\text { melihat, dan membaca } \\
\text { pesan-pesan yang }\end{array}$ & Durasi & $\begin{array}{l}\text { Jumlah waktu dalam menggunakan } \\
\text { kanal DetikPEMILU pada portal } \\
\text { berita }\end{array}$ & \\
\hline
\end{tabular}




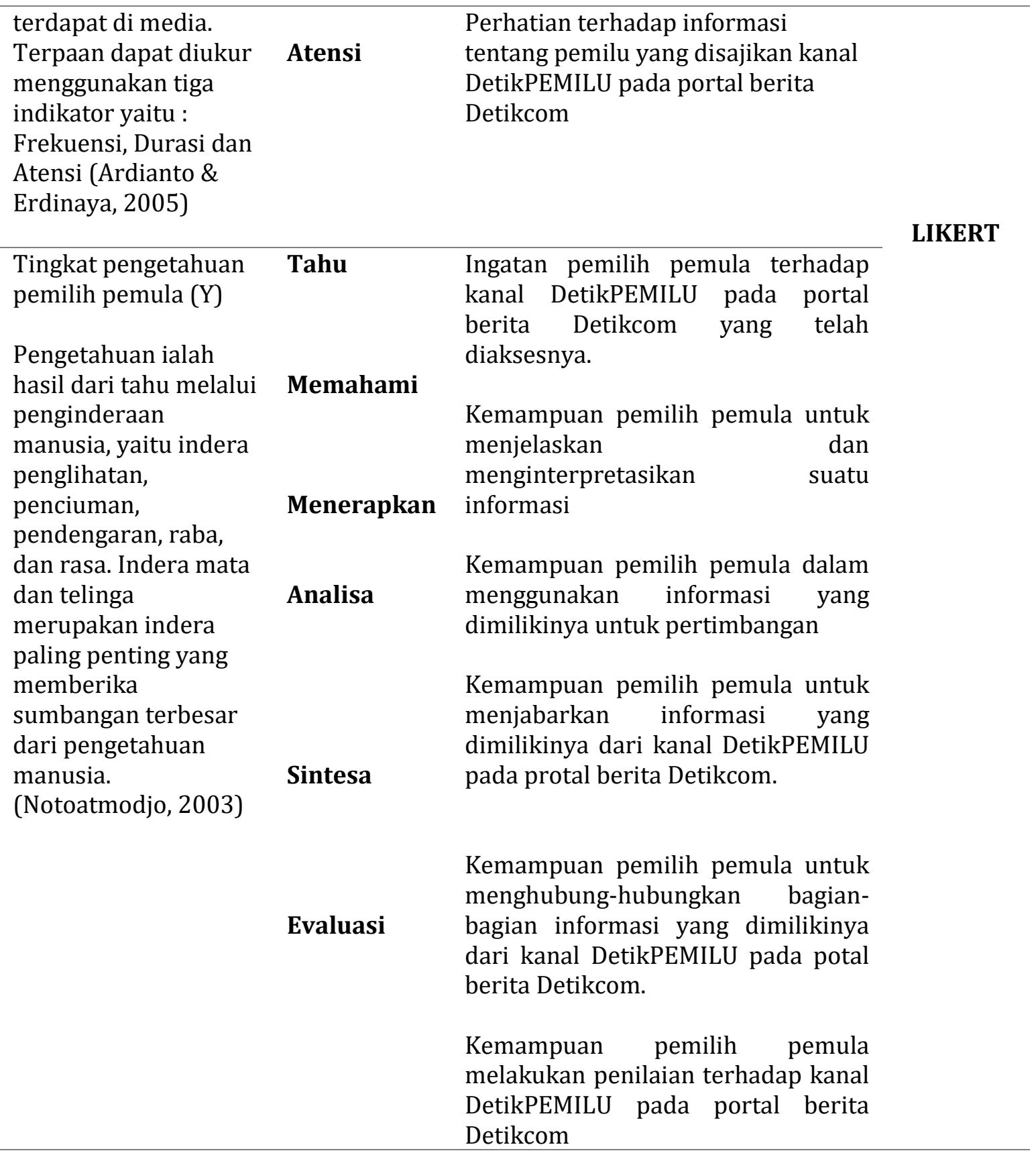

Sumber: Ardianto \& Erdinaya, (2005) \& Notoatmodjo (2003)

\section{HASIL DAN PEMBAHASAN}

Portal berita Detikcom adalah satusatunya portal berita yang menyediakan kanal khusus pemilu yang diberi nama
DetikPEMILU. Didalamnya terdapat berbagai informasi mengenai pemilu yang dikupas secara cepat, faktual, dan 
berimbang. Kanal DetikPEMILU adalah sebuah sub bagian berita yang terdapat pada portal berita Detikcom yang memuat semua informasi tentang pemilihan umum yang dilaksanakan pada 17 April 2019.

Kanal DetikPEMILU pada periode Februari 2019 memuat informasi seputar kegiatan masa kampanye dan debat kandidat pasangan calon presiden dan wakil presiden. Dimana semua informasi yang berhubungan dengan para calon kandidat terutama pada saat masa kampanye dan debat sangat dibutuhkan oleh khalayak, termasuk para pemilih pemula.

Pada penelitian ini sebanyak 17 Pertanyaan yang dibagikan kepada responden, masing-masing pertanyaan tersebut telah diuji validitas dan reliabilitasnya. Adapun Responden yang terlibat dalam penelitian ini terdiri dari $31.6 \%$ laki-laki sedangkan $68.4 \%$ perempuan dengan dominasi usia responden 18 Tahun atau persentase sebesar $46.1 \%$.

Uji Korelasi menunjukan bahwa Kanal DetikPEMILU memiliki hubungan yang kuat dengan tingakt pengetahuan pemilih pemula, berdasarkan perhitungan SPSS versi 23 terdapat nilai korelasi $r$ yaitu $=$ 0,666 . Sehingga, jika mengacu pada tabel tingkat korelasi dan kekuatan hubungan nilai tersebut memiliki arti hubungan yang kuat karena terletak diantara 0,600 $-0,799$.
Tabel.2 Hasil Uji Korelasi Variabel X dan Y

\begin{tabular}{|c|c|c|c|c|}
\hline \multicolumn{5}{|c|}{ Correlations } \\
\hline & & & Terpa & Tingk \\
\hline & & & an & \\
\hline & & & kanal & Penge \\
\hline & & & Detik & tahua \\
\hline & & & PEMI & $\mathrm{n}$ \\
\hline & & & LU & Pemil \\
\hline & & & & \\
\hline & & & & Pemu \\
\hline & & & & la \\
\hline \multirow{20}{*}{$\begin{array}{l}\text { Spea } \\
\text { rman } \\
\text { 's } \\
\text { rho }\end{array}$} & \multirow{10}{*}{$\begin{array}{l}\text { Terpa } \\
\text { an } \\
\text { Kanal } \\
\text { Detik } \\
\text { PEMI } \\
\text { LU }\end{array}$} & Corr & 1.000 & $.666^{*}$ \\
\hline & & elati & & * \\
\hline & & on & & \\
\hline & & Coefi & & \\
\hline & & cient & & \\
\hline & & Sig. & & .000 \\
\hline & & $(2-$ & & \\
\hline & & taile & & \\
\hline & & d) & & \\
\hline & & $\mathrm{N}$ & 76 & 76 \\
\hline & \multirow{10}{*}{$\begin{array}{l}\text { Tingk } \\
\text { at } \\
\text { Penge } \\
\text { tahua } \\
\text { n } \\
\text { Pemili } \\
\text { h } \\
\text { Pemul } \\
\text { a }\end{array}$} & Corr & $.666^{* *}$ & 1.000 \\
\hline & & elati & & \\
\hline & & on & & \\
\hline & & Coefi & & \\
\hline & & cient & & \\
\hline & & Sig. & .000 & \\
\hline & & $(2-$ & & \\
\hline & & taile & & \\
\hline & & d) & & \\
\hline & & $\mathrm{N}$ & 76 & 76 \\
\hline
\end{tabular}


**. Correlations is significant at the 0.01 level (2-tailed).

Sumber: Hasil Olah Data Melalui SPSS

versi 23

Selain uji korelasi di atas, uji determinasi juga dilakukan peneliti untuk melihat ada tidaknya pengaruh antara terpaan detikPEMILU terhadap tingkat pengetahuan pemilih pemula, Nilai yang dihasilkan dari uji korelasi determinasi akan menunjukkan presentase besarnya kontribusi antara variabel independen (variabel bebas) terhadap variabel dependen (variabel terikat).

Namun sebelum menentukan uji determinasi, terlebih dulu peneliti mencari koefisien determinasi melalui rumus dibawah ini :

$$
\begin{aligned}
\mathrm{Kd} & =r^{2} \times 100 \% \\
& =0,666^{2} \times 100 \% \\
& =0,443 \times 100 \% \\
& =\mathbf{4 4 , 3} \%
\end{aligned}
$$

Berdasarkan hasil perhitungan dari koefisien determinasi, nilai korelasi $(\mathrm{r})=$ 0,666 dan penguadratan nilai korelasi yaitu $44,3 \%$ dapat dikatakan bahwa ada pengaruh antara terpaan kanal DetikPEMILU terhadap tingkat pengetahuan pemilih pemula, namun pengaruh tersebut tidak signifikan.

Selanjutnya peneliti melakukan uji t, uji tersebut dilakukan untuk menguji signifikansi koefisien korelasi variabel $\mathrm{X}$ (pengaruh terpaan kanal DetikPEMILU) dengan variabel $Y$ (tingkat pengetahuan pemilih pemula). Melalui penggunaan rumus dibawah ini:

$$
t=\mathrm{r} \frac{\sqrt{n-2}}{\sqrt{1-r^{2}}}
$$

$t=\frac{0,666 \sqrt{76-2}}{\sqrt{\left(1-0.666^{2}\right)}}$

$t=\frac{0,666 \sqrt{74}}{\sqrt{1-0,443}}$

$t=\frac{0,666 \sqrt{74}}{\sqrt{0,557}}$

$t=\frac{0,666 \times 8,602}{0,746}$

$t=\frac{5,728}{0,746}$

$t=7,678$

Berdasarkan perhitungan dengan menggunakan Uji $t$, maka diperoleh $t$ hitung yaitu sebesar 7,678. Penentuan kesimpulan signifikasi dengan membandingkan $\mathrm{t}$ hitung dengan $\mathrm{t}$ tabel yaitu penentuan level of signification, dari t tabel nilainya ditentukan pada tingkat signifikasi $10 \%$ dan $\mathrm{df}=\mathrm{n}-2$ yaitu $76-2=$ 74. Dengan demikian t tabel adalah 1,666. Dengan demikian $t$ tabel adalah 1,666. Berdasarkan perhitungan tersebut, hasil perhitungan thitung 7,678 > t tabel 1,666. Maka dapat disimpulkan Ho ditolak dan Ha diterima yang artinya pengaruh terpaan kanal DetikPEMILU periode Februari 2019 pada portal berita Detikcom berpegaruh terhadap tingkat pengetahuan pemilih pemula siswa/i kelas XII SMAN 12 Tangerang Selatan. 


\section{Penutup}

Berdasarkan hasil penelitian, maka dapat disimpulkan sebagai berikut:

1. Terdapat pengaruh terpaan kanal DetikPEMILU periode Februari 2019 pada portal berita Detikcom tingkat pengetahuan pemilih pemula berdasarkan hasil perhitungan uji hipotesis yaitu sebesar 7,678, yang mana thitung $(8,912)>\operatorname{tabel}(1,660)$ sehingga Ho ditolak dan Ha diterima (ada pengaruh).

2. Hasil besarnya pengaruh terpaan kanal DetikPEMILU periode Februari 2019 pada portal berita Detikcom terhadap tingkat pengetahuan pemilih pemula (survei pada siswa/i kelas XII SMAN 12 Tangerang Selatan) dilihat dari perolehan nilai koefisiren determinasi yaitu sebesar 44,3\% tingkat pengetahuan pemilih pemula siswa/i kelas XII SMAN 12 Tangerang Selatan ditentukan oleh kanal DetikPEMILU pada portal berita Detikcom, namun pengaruh tersebut tidak signifikan dan sisanya 55,7\% ditentukan oleh faktor lain yang tidak diteliti. 


\section{DAFTAR PUSTAKA}

Ardianto, E., \& Erdinaya, L.K. 2005. Komunikasi Massa: Suatu Pengantar. Bandung: PT Remaja Rosdakarya.

Azwar. 2018. Empat Pilar Jurnalistik: Pengetahuan Dasar Belajar Jurnalistik. Jakarta: Prenada Media Kencana.

Baran, S.J., \& Davis, D.K. 2000. Teori Komunikasi Massa, Dasar, Pergolakan, dan Masa

Depan. (Terjemahan) Edisi 5. Jakarta: Salemba Humanika.

Budiardjo, M. 2009. Dasar-Dasar IImu Politik. Edisi revisi. Jakarta: Gramedia Pustaka Utama.

Detik.com. 2018. Ada 5 Juta Pemilih

Pemula di

Pemilu 2019.

https://news.detik.com/berita/d4215354/ada-5-juta-pemilihpemula-di-pemilu-2019

Institute, Reuters. (2017). Kawula Muda Akses Berita Lewat Medsos. https://databoks.katadata.co.id/d atapublish/2017/04/12/reutersin stitutekawula muda-akses-beritalewat-medsos

Kriyantono, R. 2008. Teknik Praktis Riset Komunikasi. Jakarta: Prenada Media Group. Liputan6.com. 2018. Ketahui Informasi Penting
Ini Agar Jadi Pemilih Pemula Cerdas dan

Berdaulat.https://www.liputan6. com/news/read/3676554/ketah ui-informasi-penting-ini-agarjadi-pemilih-pemula-cerdas-danberdaulat

Media, Batic. 2018. Pembaca Media Online Naik 500 Persen. https://www.baticmedia.com/20 18/2/pembacamediaonlinenaik5 00persn.html

Notoatmodjo, Soekidjo, 2003, Pengembangan Sumber Daya Manusia, Jakarta: PT. Rineka Cipta.

Saifudin, A. 2002. Sikap Manusia Teori dan Pengukurannya. Yogyakarta:

Pustaka Pelajar.

Sani, A., dan Masyhuri. 2010. Metodologi Riset Sumber Daya Manusia.

Malang: UIN MALIKI

PRESS.

Sugiono. 2016. Metode Penelitian Kuantitatif, Kualitatif dan $R \& D$. Bandung:

Penerbit Alfabeta.

Sujarweni, V, W. 2014. Metodologi Penelitian. Yogyakarta.: Pustaka Baru Press. 